\title{
Parameters optimization of crop protection UAS based on the first industry standard of China
}

\author{
Songchao Zhang ${ }^{1,2,3}$, Baijing Qiu ${ }^{1,2 *}$, Xinyu Xue ${ }^{3 *}$, Tao Sun ${ }^{3}$, Bin Peng ${ }^{4}$ \\ (1. Key Laboratory of Modern Agricultural Equipment and Technology, Ministry of Education, Jiangsu University, Zhenjiang 212013, China; \\ 2. Key Laboratory of Plant Protection Engineering, Ministry of Agriculture and Rural Affairs, Zhenjiang 212013, China; \\ 3. Nanjing Institutes for Agricultural Mechanization, Ministry of Agriculture and Rural Affairs, Nanjing 210014, China; \\ 4. Guangzhou XAG Co., Ltd, Guangzhou 510663, China)
}

\begin{abstract}
The effective swath width (ESW) and the droplet penetration rate (DPR) directly affect the spraying quality, the spraying efficiency and the control effect of pests and diseases during the crop protection unmanned aircraft system (CPUAS) application. However, the ESW and DPR are not constant with the changes of the flight speed (FS) and the flight height (FH). In order to investigate the ESW and DPR of the CPUAS P20, four levels of FS $(3 \mathrm{~m} / \mathrm{s}, 4 \mathrm{~m} / \mathrm{s}, 5 \mathrm{~m} / \mathrm{s} \mathrm{and} 6 \mathrm{~m} / \mathrm{s})$ and three levels of FH (1.5 m, $2.0 \mathrm{~m}$ and $2.5 \mathrm{~m})$ experiments were carried out according to the first industry standard of China for the CPUAS in the wheat field. The results demonstrated that the ESWs were negatively correlated with the FS and the FH. Most of the ESWs were over $2 \mathrm{~m}$ in the 12 treatments, in which the maximum one was $3.25 \mathrm{~m}(3 \mathrm{~m} / \mathrm{s}, 1.5 \mathrm{~m})$. The DPRs were negatively correlated with the FH under the same FS, the average value of the DPRs was $48.37 \%$, in which the maximum one was $78.34 \%$ $(4 \mathrm{~m} / \mathrm{s}, 1.5 \mathrm{~m})$ and the minimum one was $25.5 \%(6.0 \mathrm{~m} / \mathrm{s}, 2.5 \mathrm{~m})$. The statistical analyses showed that the FS had significant impacts on the ESWs $(0.01<p$-value $<0.05)$ while there were no significant differences among different FH treatments $(p$-value $>0.05$ ). The impacts of both FS and FH on the DPRs were extremely significant ( $p$-value $<0.01$ ), and the interactive impacts were significant $(0.01<p$-value $<0.05)$. Therefore, it is concluded that reducing the FS could increase the ESWs, and reducing the FH could increase the DRPs at the same FS. In conclusion, the maximum spraying efficiency of P20 was $4.342 \mathrm{hm}^{2} / \mathrm{h}$ with $6 \mathrm{~m} / \mathrm{s} \mathrm{FS}$ and $1.5 \mathrm{~m} \mathrm{FH}$ in case of satisfying the requirement of DPRs. This study provided scientific references for guiding the CPUAS spraying.
\end{abstract}

Keywords: crop protection unmanned aircraft system, standard, effective swath width, penetration, parameter optimization DOI: $10.25165 /$ j.ijabe.20201303.5439

Citation: Zhang S C, Qiu B J, Xue X Y, Sun T, Peng B. Parameters optimization of crop protection UAS based on the first industry standard of China. Int J Agric \& Biol Eng, 2020; 13(3): 29-35.

\section{Introduction}

The CPUAS has the advantages of superior mobility, wide adaptability and high efficiency without the restrictions of the crop types or growth periods, especially suits for the paddy fields and the mountainous areas ${ }^{[1-3]}$. Benefit from the development of the modern electronic communication, the control technologies ${ }^{[4-6]}$ and the national policy ${ }^{[7]}$, the CPUAS has developed rapidly in China in recent years ${ }^{[7,8]}$, not only the technical level but also the application area are already the first around the world ${ }^{[9,10]}$.

The ESW and DPR are two important indicators in the CPUAS application, directly affect the spraying quality, the spraying efficiency and the control effect. In the past few years, some studies have been undertaken to investigate and improve the CPUAS application. Huang et al. ${ }^{[11]}$ used a simulation-based

\section{Received date: 2019-10-02 Accepted date: 2020-03-12}

Biographies: Songchao Zhang, MS, research interests: precise pesticide spraying, Email: 51832898@qq.com; Tao Sun, MS, research interests: precise pesticide spraying, Email: 2260559763@qq.com; Bin Peng, BS, research interests: detection and control, Email: pengbin@xair.cn.

*Corresponding author: Baijing Qiu, PhD, Professor, research interest: crop protection and machinery engineering, Key Laboratory of Modern Agricultural Equipment and Technology, Ministry of Education, Jiangsu University, Zhenjiang 212013, China, Tel: +86-511-88797338, Email: qbj@ujs.edu.cn; Xinyu Xue, $\mathrm{PhD}$, Professor, research interest: crop protection and machinery engineering, Nanjing Institute for Agricultural Mechanization, Ministry of Agriculture and Rural Affairs, Nanjing 210014, China. Tel: +86-25-84346243, Email: xuexynj@qq.com. approach to study the aerially applied crop protection drift, and set a near-optimal offset of the flight trajectory to reduce the drift and increase the near deposition. Qiu et al. ${ }^{[12]}$ arranged a test by two factors three levels to find out the factors and degree of influence affecting the CPUAS spraying deposition. The results showed that the FH, FS and the interaction between the two factors all affected the deposition and uniformity. Xue et al. ${ }^{[13]}$ carried out trails to measure the aerial spray deposition and drift in the paddy field, the results showed with the assistant of the downwash of the rotors, the under layer deposition could take up of $92.8 \%$ of the upper one and $90 \%$ drift droplets were located within a range of 8 $\mathrm{m}$. Al-Heidary et al. $^{[14]}$ discussed the droplet and spraying to investigate the influence on field sprayer drift, including droplet size, droplet velocity, droplet evaporation, droplet diameter distribution and spraying height, spraying top angle, which provide a reference to the aerial spraying. Zhang et al. ${ }^{[15]}$ proposed a new approach based on computational fluid dynamics (CFD) to investigate the aerial spraying drift when the FS was $3 \mathrm{~m} / \mathrm{s}$, FHs were $5 \mathrm{~m}, 6 \mathrm{~m}$ and $7 \mathrm{~m}$. The study proved that the approach was feasible and suggested that buffer zone should be reserved considering the downwind drift. Hou et al. ${ }^{[16]}$ designed the parameter controller of the CPUAS for improving the droplet density on citrus trees, and the experimental results showed that the FS presented the most significant effect, the established model predicted an optimal spraying height of $1.27 \mathrm{~m}$ and maximum droplet density of 35.39 droplets $/ \mathrm{cm}^{2}$. Wang et al. ${ }^{[17]}$ used three measurement methods(sampling frame, Petri dishes, rotary 
impactors) to test the sediment and aerial spraying drift under different FH, FS and wind speed, the analysis results could provide data support for the CPUAS application under different conditions.

These studies indicated that appropriate operation parameters could improve the pesticide droplet deposition and the penetration, thereby achieved a fine control effect of pests and diseases. However, the ESW and the DPR vary with the FH and FS, while in actual the application of the CPUAS the ESW usually was determined by the manufacturer's suggestions or the experiences of the operators ${ }^{[18]}$, ignoring the influences of parameters. Therefore, studying the effects of different heights and speeds on the ESWs and DPRs can guide the CPUAS to spray pesticides better, reducing the pesticide usage and improving the pesticide utilization efficiency.

Due to the lack of standards special for the CPUAS, some results and conclusions were concluded and tested according to some relevant standards as ASAE S3451.3, MH/T1002 and MH/T1040 ${ }^{[18-21]}$, which had a certain reference significance for the CPUAS application.

The first agricultural industry standard Technical Specification of Quality Evaluation for Crop Protection UAS was promulgated on June 1st, 2018 in China ${ }^{[22]}$, which is the most authoritative worldwide until now. In this article, four levels of FS and three levels of FH experiments were carried out to test the ESWs and DPRs of the CPUAS P20 (Guangzhou XAG Co., Ltd, China) in the wheat field. The aims were to understand the spraying quality under different parameter conditions and determine the optimal parameter combinations for the CPUAS application, providing a decision basis for controlling pests and diseases in different parts and growth periods of the crops.

\section{Materials and methods}

\subsection{Test site and the environment}

The experiments were carried out in the wheat field of Sihong agricultural demonstration base $\left(33.3636^{\circ} \mathrm{N}, 118.2599^{\circ} \mathrm{E}\right)$ in Jiangsu Province, China, on April 16, 2019. The wheat variety is Qianmai 33, and was sowed in the field $(60 \mathrm{~m} \times 120 \mathrm{~m})$ with seed rate $225 \mathrm{~kg} / \mathrm{hm}^{2}$. The wheat was on the growth period of heading stage with an average $65 \mathrm{~cm}$ height. The wind speed ranged among 0.5 to $1.5 \mathrm{~m} / \mathrm{s}$, the average temperature was about $14^{\circ} \mathrm{C}$ and the average relative humidity was $65 \%$, which met the test condition requirements of the CPUAS swath width.

\subsection{Experimental equipment and materials}

The main parameters of $\mathrm{P} 20$ are shown in Table 1 . The portable weather meter Kestrel 4500 (the Nielsen-Kellerman company, US.) was used to record the wind speed, the temperature and the relative humidity. The Rhodamine B solution with $0.05 \%$ mass fraction was sprayed in the experiments. Droplets were collected by the water sensitive paper (WSP). The DepositScan (DS) software ${ }^{[19,23]}$ was used for analyzing droplet deposition density and coverage.

Table 1 Main parameters of the CPUAS P20

\begin{tabular}{lcc}
\multicolumn{1}{c}{ Parameters } & Values & Remarks \\
\hline $\mathrm{FS} / \mathrm{m} \cdot \mathrm{s}^{-1}$ & $0-6$ & $3-6$ usually \\
$\mathrm{FH} / \mathrm{m}$ & $0.5-3.0$ & $1.5-2.5$ usually \\
Maximum load $/ \mathrm{L}$ & 10 & $/$ \\
Total spraying volume $/ \mathrm{L} \cdot \mathrm{hm}^{-2}$ & 10.5 & Recommended \\
Number of nozzles & 2 & Centrifugal \\
\hline
\end{tabular}

\subsection{Sampling arrangements}

The experiments were designed according to the standard Technical Specification of Quality Evaluation for Crop Protection UAS (NY/T3213-2018). The whole experimental area was divided into flight acceleration area, sampling area and stop spraying area. The flight acceleration area and the stop spraying area were both $50 \mathrm{~m}$ long in order to ensure the P20 could accelerate to a predetermined speed and stop timely. Three repetitions in the sample area with a $10 \mathrm{~m}$ interval were arranged along the vertical direction of the flight route. A total of 15 sampling points were arranged on each line. The sampling points labeled S1 to S15 were symmetrically distributed from left to right on both sides of the flight route. To the experiences, the ESWs of P20 would be not less than $1.5 \mathrm{~m}$, so the interval distances among $\mathrm{S} 1$ to $\mathrm{S} 6$ were set as $0.20 \mathrm{~m}$, S6 to $\mathrm{S} 7$ were set as $0.25 \mathrm{~m}$, and S7 to $\mathrm{S} 8$ were set as $0.50 \mathrm{~m}$ for improving the experiment efficiency (the right side sampling points arranged same as the left side ones). The sampling layout was set as Figure 1 showed.

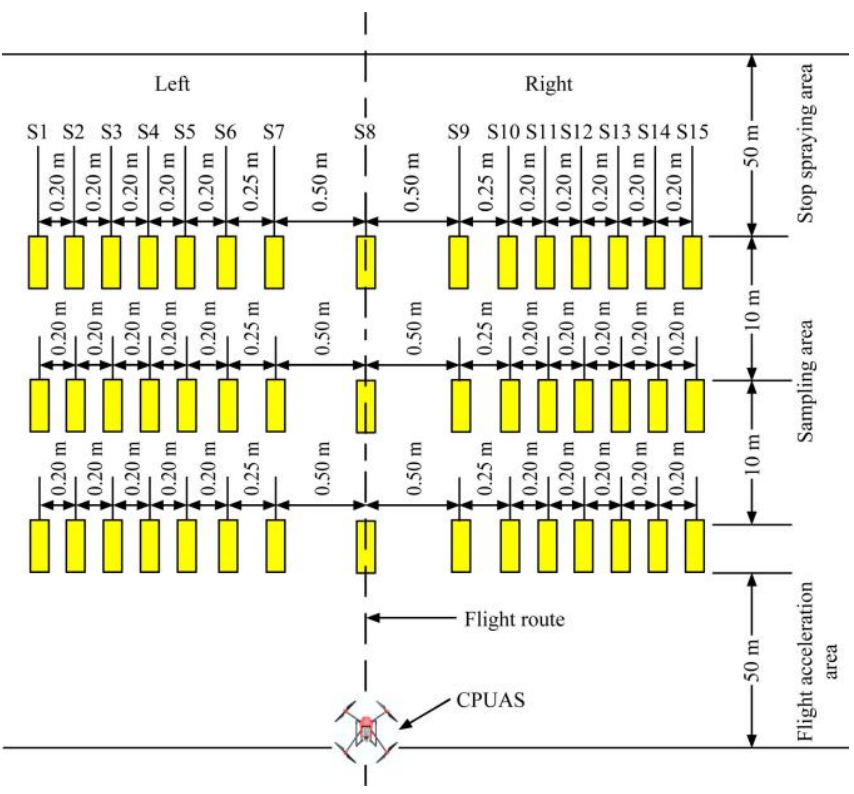

Figure 1 Layout of droplet sampling cards (top view)

The WSPs were fixed horizontally on the upper and lower layers at each sampling point without overlapping as Figure 2 showed, $15 \mathrm{~cm}$ vertical distance both to the top canopy of the wheat and the ground. The swath widths were measured by the collecting droplets from the upper layer WSPs and the penetration rates were calculated by the collecting droplets from both the upper and layer WSPs. When each spraying test was finished, the WSPs were collected and put into the self-sealing bags and brought back to the laboratory for analysis.

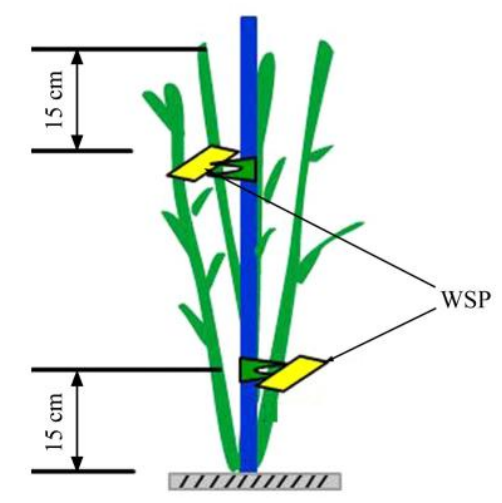

Figure 2 Sketches of WSPs fixed for collecting droplets 


\subsection{Experimental treatments}

Considering the actual applications, the FS was set four levels of $3 \mathrm{~m} / \mathrm{s}, 4 \mathrm{~m} / \mathrm{s}, 5 \mathrm{~m} / \mathrm{s}$ and $6 \mathrm{~m} / \mathrm{s}$, the FH was set three levels of $1.5 \mathrm{~m}, 2.0 \mathrm{~m}$ and $2.5 \mathrm{~m}$. The CPUAS P20 flew from the acceleration area to the stop spraying area perpendicularly along the center line of the sampling area with autonomous mode ${ }^{[4]}$. Twelve treatments (A1 to A3, B1 to B3, C1 to C3, D1 to D3) with different parameter combinations were carried out. All the treatment parameters are showed in Table 2. The flow volume per unit is constant recommended in Table 1 as the spraying rate matches with the FS.

Table 2 Test program

\begin{tabular}{ccc}
\hline Treatments & FS/m·s & FH $/ \mathrm{m}$ \\
\hline A1 & 3 & 1.5 \\
A2 & 3 & 2.0 \\
A3 & 3 & 2.5 \\
B1 & 4 & 1.5 \\
B2 & 4 & 2.0 \\
B3 & 4 & 2.5 \\
C1 & 5 & 1.5 \\
C2 & 5 & 2.0 \\
C3 & 5 & 2.5 \\
D1 & 6 & 1.5 \\
D2 & 6 & 2.0 \\
D3 & 6 & 2.5 \\
\hline
\end{tabular}

\subsection{Statistical analysis}

The WSPs were scanned to JPG images as shown in Figure 3. The droplet coverage density on each WSP was calculated by the DS, the deposition uniformity and penetration rate were analyzed further.

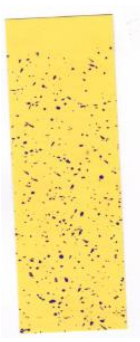

a. Upper WSPs

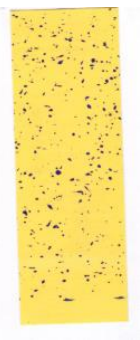

Figure 3 WSPs collecting the droplets
The first sampling point of droplet quantity not less than 15 droplets per square centimeters $\left(\mathrm{cm}^{2}\right)$ was judged as the boundary of the ESW each line. If the quantities of the two adjacent sampling points jump changed, such as the current point's droplet quantity was far more than 15 droplets $/ \mathrm{cm}^{2}$, while the next one was less than 15 droplets $/ \mathrm{cm}^{2}$, interpolation processing was carried out to calculate the effective spray amplitude boundary.

The deposition uniformity was evaluated with the coefficient variation $(\mathrm{CV})$ of coverage rates ${ }^{[24]}$ on the WSPs calculated from the DS within the ESW. The CV calculation equation is as follows.

$$
\begin{gathered}
C V=\frac{S}{\bar{X}} \times 100 \% \\
S=\sqrt{\sum_{i=1}^{n} \frac{\left(X_{i}-\bar{X}\right)^{2}}{(n-1)}}
\end{gathered}
$$

where, $S$ is the standard deviation of the droplet coverage rates on the WSPs each repetition; $X_{i}$ is the coverage rate of each WSP in the repetition, and $\bar{X}$ is the average of $X_{i}$.
The droplet penetrability into the canopies was expressed by the DPR calculated by the following equation.

$$
\eta=\frac{x_{i}}{X_{i}} \times 100 \%
$$

where, $x_{i}, X_{i}$ are the coverage of the upper layer WSP and the lower WSP each sampling point within the ESW range; $\eta$ is the penetration rate, respectively.

\section{Results and analysis}

\subsection{Test result data}

The maximum and average swath widths were calculated which were the maximum and average ones of the three repetitions in each treatment, respectively. The $C V$ of coverage rates and the penetration rate were calculated according to Equations (1)-(3). In this article, the average swath width was used as the ESW in order to ensure accuracy. The test result data were shown in Table 3 .

Table 3 Test result data of swath widths, droplet deposition uniformities and penetration rates

\begin{tabular}{ccccc}
\hline $\begin{array}{c}\text { Treatment } \\
\text { number }\end{array}$ & $\begin{array}{c}\text { Average swath } \\
\text { width/m }\end{array}$ & $\begin{array}{c}\text { Maximum swath } \\
\text { width/m }\end{array}$ & CV/\% & $\eta / \%$ \\
\hline A1 & $\mathbf{2 . 9 6}$ & $\mathbf{3 . 2 5}$ & 72.57 & 62.80 \\
A2 & 2.81 & 3.00 & 70.62 & 47.78 \\
A3 & 2.70 & 2.90 & 75.42 & 46.30 \\
B1 & 2.43 & 2.88 & 65.19 & $\mathbf{7 8 . 3 4}$ \\
B2 & 2.31 & 2.80 & $\mathbf{5 2 . 9 1}$ & 60.48 \\
B3 & 2.20 & 2.68 & 56.89 & 52.12 \\
C1 & 2.13 & 2.70 & 56.24 & 49.16 \\
C2 & 2.09 & 2.58 & $\mathbf{9 6 . 7 7}$ & 36.31 \\
C3 & 1.98 & 2.45 & 59.59 & 28.55 \\
D1 & 2.01 & 2.48 & 76.17 & 53.64 \\
D2 & 1.88 & 2.35 & 61.51 & 39.57 \\
D3 & $\mathbf{1 . 7 9}$ & $\mathbf{2 . 2 3}$ & 55.87 & $\mathbf{2 5 . 5 0}$ \\
\hline
\end{tabular}

Note: $C V$ represents coefficient variation calculated by Equations (1) and (2), $\eta$ represents the droplet penetration rate calculated by Equation (3).

From the Table 3, it could be seen that the ESWs are among $1.79 \mathrm{~m}$ (D3) to $2.96 \mathrm{~m}$ (A1) which did not reach to $3 \mathrm{~m}$, and the maximum swath width of each treatment was more than $2 \mathrm{~m}$, of which the maximum one was $3.25 \mathrm{~m}$ (A1). The $C V \mathrm{~s}$ were all exceeding $50 \%$ of which the minimum one was $52.91 \%$ (B2) and the maximum one was $96.77 \%(\mathrm{C} 2)$, which meant the deposition uniformity fluctuated greatly within the ESWs. The DPRs of the twelve treatments had no obvious correlation with the changes of the FSs, of which the maximum value was $78.34 \%$ (B1) and the minimum one was $25.50 \%$ (D3).

\subsection{ESW analyses}

\subsubsection{ESW changes}

Figures 4 and 5 show the change trends of the ESWs with the changes in heights and speeds. Obviously, the ESWs decreased with the increase in the speeds. Taking the height of $1.5 \mathrm{~m}$ as an example, the ESW was $2.96 \mathrm{~m}$ at the FS of $3 \mathrm{~m} / \mathrm{s}, 2.43 \mathrm{~m}$ at the FS of $4 \mathrm{~m} / \mathrm{s}, 2.13 \mathrm{~m}$ at the FS of $5 \mathrm{~m} / \mathrm{s}$ and $2.01 \mathrm{~m}$ at an FS of $6 \mathrm{~m} / \mathrm{s}$, respectively. The same trends were observed in Figure 5 (ESW1.5, ESW2.0, ESW2.5), the ESWs decreased with the increase of the heights at the same speeds. Therefore, it could be considered that the FH and the FS affected the ESWs.

Comparing Figure 4 with Figure 5, it could be seen that the ESWs with the same height varied much more than the ones at the same speed. 


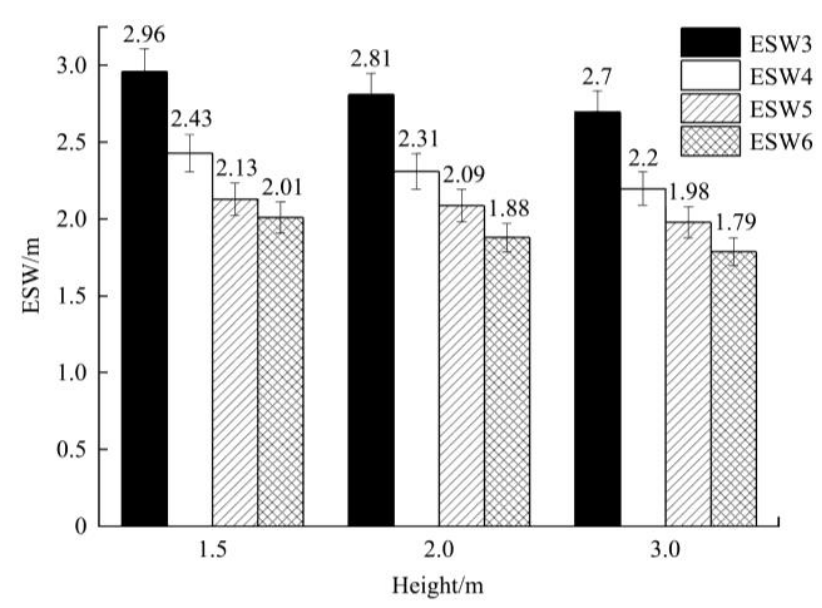

Note: ESW3, ESW4, ESW5, ESW6 represent the ESW when the FS is $3 \mathrm{~m} / \mathrm{s}, 4 \mathrm{~m} / \mathrm{s}, 5 \mathrm{~m} / \mathrm{s}$ and $6 \mathrm{~m} / \mathrm{s}$, respectively.

Figure 4 ESW changes under different heights

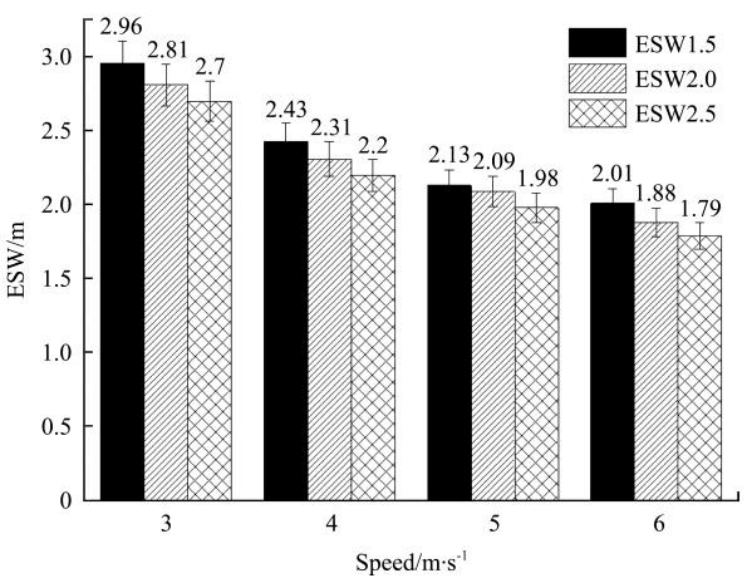

Note: ESW1.5, ESW2.0, ESW2.5 represent the ESW when the FH was $1.5 \mathrm{~m}, 2.0 \mathrm{~m}$ and $2.5 \mathrm{~m}$, respectively.

Figure 5 ESW changes under different speeds

\subsubsection{Effects of FS and FH on ESWs}

By the two-way analysis of variance (ANOVA) results, the ESWs were significantly affected by the FS, while the FH effect and the interactive effect between FS and FH were non-significant (Table 4).

The ESW decrease rates were calculated under the same FH with different FSs and the same FS with different FHs. The ESWs decreased by $17.91 \%$ (compare B1 with A1), $12.35 \%$ (compare $\mathrm{C} 1$ with $\mathrm{B} 1$ ) and $5.63 \%$ (compare $\mathrm{D} 1$ with $\mathrm{C} 1$ ) under the $1.5 \mathrm{~m} \mathrm{FH}, \quad 17.79 \%$ (compare B2 with A2), $9.52 \%$ (compare C2 with B2) and $10.05 \%$ (compare D2 with $\mathrm{C} 2$ ) under the $2.0 \mathrm{~m} \mathrm{FH}$, $18.52 \%$ (compare B3 with A3), 10.00\% (compare C3 with B3) and $9.60 \%$ (compare D3 with $\mathrm{C} 3$ ) under the $2.5 \mathrm{~m} \mathrm{FH}$, respectively. However, the ESWs decreased by $5.07 \%$ (compare A2 with A1) and $3.91 \%$ (compare A3 with A2) under $3.0 \mathrm{~m} / \mathrm{s} \mathrm{FS}, 4.94 \%$ (compare B2 with B1) and 4.76\% (compare B3 with B2) under $4.0 \mathrm{~m} / \mathrm{s} \mathrm{FS}, 1.88 \%$ (compare $\mathrm{C} 2$ with $\mathrm{C} 1$ ) and $5.26 \%$ (compare $\mathrm{C} 3$ with C2) under $5.0 \mathrm{~m} / \mathrm{s}$ FS, $6.47 \%$ (compare D2 with D1) and $4.79 \%$ (compare D3 with D2) under $3.0 \mathrm{~m} / \mathrm{s}$ FS, respectively. The decrease rate changes were consistent with the significant analysis.

Table 4 Two-way analysis of variance for ESWs

\begin{tabular}{ccccc}
\hline Source of variance & df & F & $p$-value & Significance \\
\hline FS & 2 & 3.28 & 0.04 & $*$ \\
FH & 3 & 1.05 & 0.36 & NS \\
FS $\times$ FH & 6 & 0.046 & 0.99 & NS
\end{tabular}

Note: * is significant at 0.05 probability level, NS=Non-significant
3.2.3 Linear mathematical relationship among the ESWs, FS and the $\mathrm{FH}$

Considering the FS $(x)$ and the $\mathrm{FH}(y)$ as the independent variables, the ESW $(Z)$ as the dependent variable for binary linear regression analysis, the correlation coefficient $R$ was 0.969 , and the coefficient of determination $R^{2}$ was 0.939 . The binary linear regression function was as bellow.

$$
Z=4.071-0.304 x-0.215 y
$$

To the function (4), the $F$ value was 69.869 , the significance $F$ value $<0.01$ in the regression analysis indicating that the regression function (4) was extremely significant $(* *)$.

Table 5 Linear regression analysis of ESW, FS and FH

\begin{tabular}{lccccc}
\hline \multicolumn{1}{c}{ Items } & df & SS & MS & $F$ & Significance $F$ \\
\hline Regression analysis & 2 & 1.476 & 0.738 & 69.869 & $3.229 \mathrm{E}-06$ \\
Residual & 9 & 0.095 & 0.010 & - & \\
Total & 11 & 1.571 & - & - & \\
\hline
\end{tabular}

\subsection{PDR analyses}

\subsubsection{The DPR changes}

The average DPR was $48.37 \%$, which indicated that the coverage of the lower layer was about to half of the upper one, and the maximum one was $78.34 \%$ (B1). The DPRs decreased with the FH increased under the same FS showed in Figure 6, while change trends were not consistent with the FS under the same FH in Figure 7. It could be concluded out the negative correlations between DPR and FH at the same FS. From this perspective, the average DPR was $60.99 \%$ at $1.5 \mathrm{~m} \mathrm{FH}, 46.04 \%$ at $2.0 \mathrm{~m}, 38.12 \%$ at $2.5 \mathrm{~m}$, indicating that $\mathrm{FH}$ was the main factor affecting penetration.

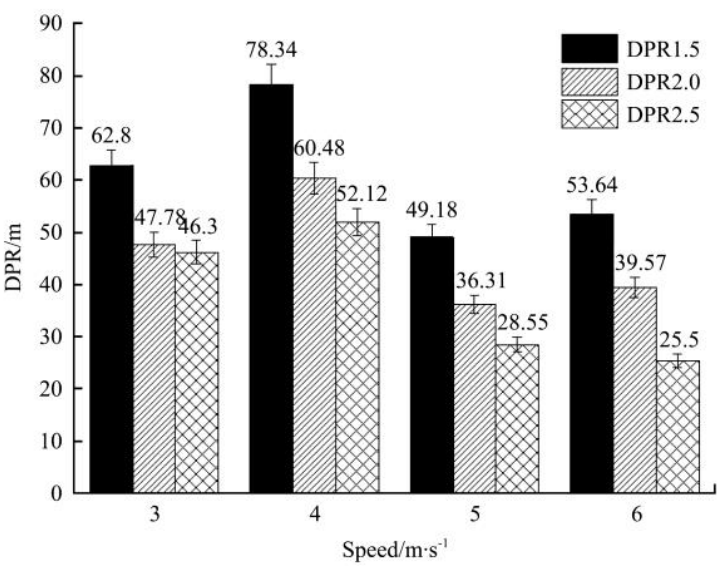

Note: DPR1.5, DPR2.0 and DPR2.5 represent the DPR when the FH was $1.5,2.0$ and $2.5 \mathrm{~m}$, respectively.

Figure 6 DPR changes under different speeds

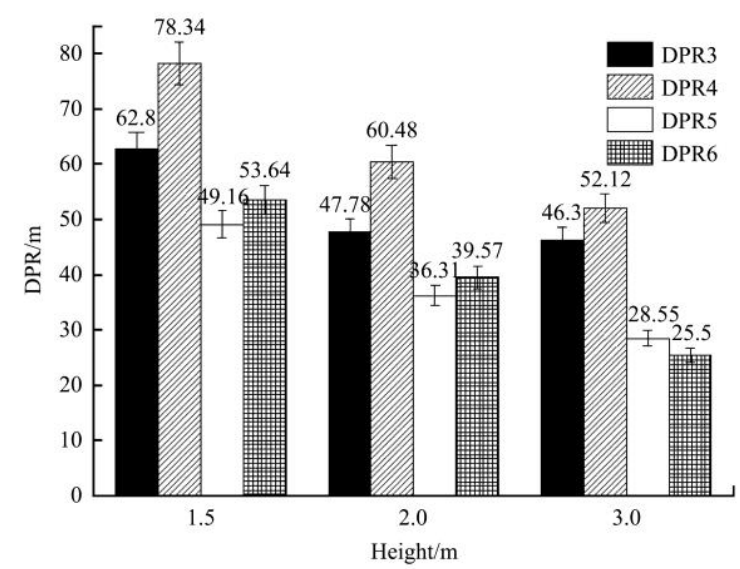

Note: DPR3, DPR4, DPR5 and DPR6 represent the DPR when the FS was $3,4,5$ and $6 \mathrm{~m} / \mathrm{s}$, respectively.

Figure 7 DPR changes under different heights 


\subsubsection{The Effects of FS and FH on DPRs}

The two-way ANOVA results (Table 6) showed that both FS and FH significantly affected the DPRs ( $p$-value $<0.01$ ) extremely, and the influence of FH on DPR was greater than that of FS. The interactive effect between FS and FH was significant $(0.01<p$-value $<0.05)$.

Table 6 Two-way analysis of variance for DPRs

\begin{tabular}{ccccc}
\hline Source of variance & df & $F$ & $p$-value & Significance \\
\hline FS & 2 & 3.28 & $1.26 \mathrm{E}-14$ & $*_{-}$ \\
FH & 3 & 1.05 & $5.69 \mathrm{E}-15$ & $* *$ \\
FS $\times$ FH & 6 & 0.046 & 0.02 & $*$ \\
\hline
\end{tabular}

Note:*,** are significant at 0.05 and 0.01 probability level, respectively.

\subsection{Droplet deposition uniformity}

The droplet deposition uniformity was as another indicator to evaluate the spraying quality. In this article, the $C V$ was used to investigate the droplet deposition uniformity by Equation (1).

The average $C V$ was $66.65 \%$ for the twelve treatments, and the average $C V \mathrm{~s}$ of treatment A $(3 \mathrm{~m} / \mathrm{s}), \mathrm{B}(4 \mathrm{~m} / \mathrm{s}), \mathrm{C}(5 \mathrm{~m} / \mathrm{s})$ and D $(6 \mathrm{~m} / \mathrm{s})$ were $72.87 \%, 58.33 \%, 70.87 \%$ and $64.52 \%$, respectively, in which the deposition uniformities at $4 \mathrm{~m} / \mathrm{s}$ (B) were best. The minimum value of the $C V \mathrm{~s}$ was $52.91 \%$ under the $4 \mathrm{~m} / \mathrm{s}$ speed and $2 \mathrm{~m}$ height (B2). The average $C V \mathrm{~s}$ for the FHs of $1.5 \mathrm{~m}, 2.0 \mathrm{~m}$ and $2.5 \mathrm{~m}$ were $67.54 \%, 70.45 \%$ and $61.94 \%$, respectively. However, the $p$-values of ANOVA analysis were larger than 0.05 taking the FS and FH as the independent variables, the $C V$ as the dependent variables, which indicated that the $C V$ variations were not affected by the changes of FSs or FHs.

Figure 8 showed the droplet deposition uniformity by $C V \mathrm{~s}$.

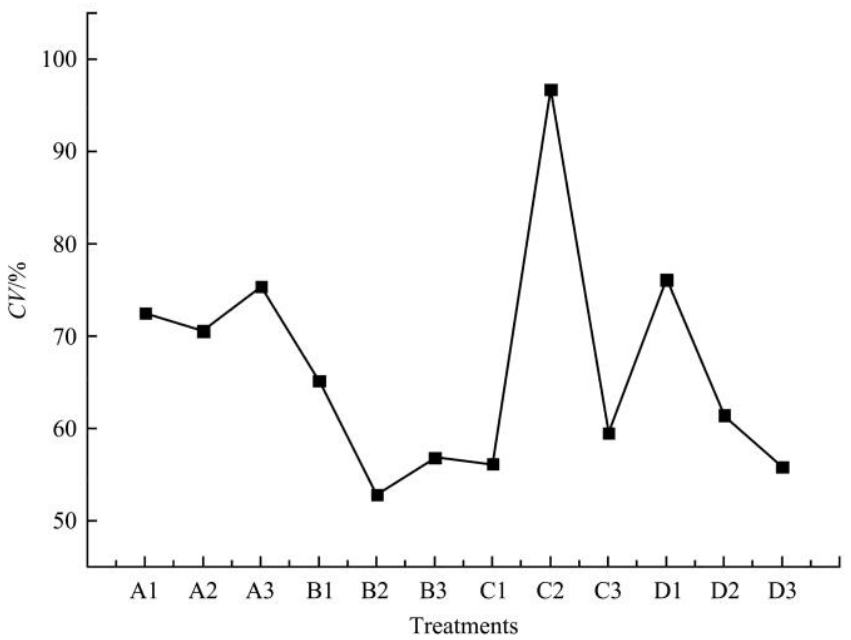

Figure 8 Deposition uniformity of each treatment by $C V \mathrm{~s}$

\subsection{Spraying efficiency}

The CPUAS spraying efficiency is accessed by the effectively sprayed area per hour calculating based on the ESW and the FS as Equation (6).

$$
S=v \times E S W \times 0.36
$$

where, $S$ is the effectively sprayed area per hour, $\mathrm{hm}^{2} / \mathrm{h} ; v$ is the FS, $\mathrm{m} / \mathrm{s}$. In Table 7 all the spraying efficiencies are calculated. The maximum efficiency is $4.342 \mathrm{hm}^{2} / \mathrm{h}$ appears in $\mathrm{S}_{6}$. When the penetrability (no larger than $53.64 \%$ ) meets the requirement, the parameter combination of D1 $(6 \mathrm{~m} / \mathrm{s}, 1.5 \mathrm{~m})$ should be preferred to ensure the maximum spraying efficiency.
Table 7 The spraying efficiencies of different treatment combinations

\begin{tabular}{cccccc}
\hline Speed $/ \mathrm{m} \cdot \mathrm{s}^{-1}$ & $\mathrm{ESW} / \mathrm{m}$ & $\mathrm{S}_{3} / \mathrm{hm}^{2} \cdot \mathrm{h}^{-1}$ & $\mathrm{~S}_{4} / \mathrm{hm}^{2} \cdot \mathrm{h}^{-1}$ & $\mathrm{~S}_{5} / \mathrm{hm}^{2} \cdot \mathrm{h}^{-1}$ & $\mathrm{~S}_{6} / \mathrm{hm}^{2} \cdot \mathrm{h}^{-1}$ \\
\hline 3 & 2.96 & 3.197 & - & - & \\
3 & 2.81 & 3.035 & - & - & - \\
3 & 2.70 & 2.916 & - & - & - \\
4 & 2.43 & - & 3.499 & - & - \\
4 & 2.31 & - & 3.326 & - & - \\
4 & 2.20 & - & 3.168 & & - \\
5 & 2.13 & - & - & 3.834 & - \\
5 & 2.09 & - & - & 3.762 & - \\
5 & 1.98 & - & - & 3.564 & - \\
6 & 2.01 & - & - & - & $\mathbf{4 . 3 4 2}$ \\
6 & 1.88 & - & - & - & 4.061 \\
6 & 1.79 & - & - & - & 3.866 \\
\hline
\end{tabular}

Note: $S_{3}, S_{4}, S_{5}$, and $S 6$ represent the spraying efficiencies at $3 \mathrm{~m}, 4 \mathrm{~m}, 5 \mathrm{~m}$ and $6 \mathrm{~m} / \mathrm{s}$, respectively.

\section{Discussion}

Different requirements are required of the deposition and penetration for different growth periods and different diseases in chemical crop protection applications because of the crop density and the disease occurrence location. Take the wheat as an example, stripe rust, powdery mildew and scab (or head blight) are the major diseases that are harmful to the wheat ${ }^{[25-27]}$. For the occurring time, the stripe rust would occur from the wheat tillering stage to the filling stage if it occurs seriously ${ }^{[31-34]}$, the powdery mildew mainly occurs between the heading stage and the milky stage of wheat ${ }^{[32-34]}$, and the scab mainly occurs from the heading stage to the filling stage ${ }^{[35]}$. For the disease occurrence locations, the stripe rust occurs in the middle and lower parts of the wheat, the powdery mildew occurs and develops from the bottom to up layer, and the scab is concentrated on the upper layer (spikelets) of wheat. Therefore, the selection of suitable operating parameters can better ensure the control effect. When controlling the scab, priority is given to increase the ESW, and the FS is appropriately reduced. When controlling the powdery mildew, the penetration of droplets is considered as an effective consideration, the FH should be reduced possibly. When controlling the stripe rust, the ESW and the penetration should be both considered for the parameter optimization combined with the growth period of wheat.

\section{Conclusions}

The ESW and DPR are two most concerned indicators to evaluate the CPUAS spraying, which represent the droplet deposition on the top canopy and inside the canopy. Achieving the accurate ESW and DPR could provide scientific references for guiding the CPUAS spraying, consequently increase the CPUAS spraying quality and reduce the pesticide waste. The FS and FH are two most important parameters in the CPUAS practical application by manual control. The parameter combination experiments suggested that the ESW and DPR of the CPUAS could be optimized by changing the FS and FH. For the CPUAS P20, the maximum ESW was $2.96 \mathrm{~m}(3 \mathrm{~m} / \mathrm{s}, 1.5 \mathrm{~m})$, the maximum DPR was $78.34 \%(4 \mathrm{~m} / \mathrm{s}, 1.5 \mathrm{~m})$. To achieve the maximum spraying efficiency, FS $6 \mathrm{~m} / \mathrm{s}$ and FH $1.5 \mathrm{~m}$ could be used. In this study, the relationships during the $\mathrm{FH}, \mathrm{FS}, \mathrm{ESW}$, DPR and the droplet deposition uniformity were studied. 
(1) The ESW is negatively correlated with the FS and FH as a whole. The ESW variations at the same FHs with different FSs are greater than those of at the FSs with different FHs. In this study, the maximum ESW variation amplitude is $0.95 \mathrm{~m}(1.5 \mathrm{~m} \mathrm{FH})$ while the maximum one is only $0.26 \mathrm{~m}(3 \mathrm{~m} / \mathrm{s} \mathrm{FS})$. The FS has significant effect on the ESW. The reason may be that when the FS is slow, the droplet initial horizontal velocity is slow, and the droplet falling is more susceptible to the rotor wind field, thus can effectively deposit on the crop canopy. However, when the FS is fast, the droplet with fast initial horizontal velocity may escape from the range of the wind field and drift away. The FH has no significant effect on the ESW. The ESW is larger when the FH is lower at the same FS. The reason may be that the droplet transport distance from release to deposition is shorter for better deposition with less evaporation. Therefore, it can be concluded that appropriately reducing the FS could effectively increase the ESW.

(2) The DPR is negatively correlated with the FH at the same FS. The DPR change trend is not monotonous at the same FH. Both FH and FS have significant effects on the DPR, and the effect of FH is greater. The reason may be that the wind field disturbs the crop making it easier for the droplet to deposit on the lower part of the exposed crop. Another reason may be that when the FH is lower the whole transport distance is shorter, the DPR is increased with the assistant of downwash of the wind field. Therefore, it can be concluded that reducing the FH could improve the droplet penetration.

(3) In this study the average $C V \mathrm{~s}$ of droplet deposition in the 12 treatments is $66.65 \%$, and the variation trend of the variation coefficient was not regular. Also, the ANOVA results showed that the uniformity of deposition was not affected by the FS or FH. The reason may be that the spraying uniformity was affected not only by FH and FS, but also by environmental wind speed, spraying volume and droplet particle size, etc, which needed further studies.

(4) The ESW is one of the most important indicators in this study, and it was tested and determined according the first industry standard of China special for the CPUAS. Some other ESW evaluation methodologies had been adopted previously, such as "minimum acceptable deposition coefficient variation values determinate method", "50\% effective application rate determinate method", "identifying the largest range of coverage rates greater than the average coverage rate method", and the results were different by different methods. In addition, the experimental results and conclusions could be as a reference basis, the influence of weather factors on the results should also be considered in actual applications.

\section{Acknowledgements}

This research was supported by the National Key Research and Development Program of China (Grant No. 2017YFD0701000), the National Natural Science Foundation of China (No.31701327), Jiangsu Agriculture Science and Technology Innovation Fund (CX(17)1002), Collaborative Innovation Plan of Scientific and Technological Innovation Project (Grant No. CAAS-XTCX2016006).

\section{[References]}

[1] Xue X Y, Qin W C, Sun Z, Zhang S C, Zhou L X, Wu P. Effects of N-3 UAV spraying methods on the efficiency of insecticides against planthoppers and Cnaphalocrocis medinalis. Acta Phytophylacica Sinica, 2013; 40(3): 273-278. (in Chinese)

[2] Qin W C, Xue X.Y, Zhou L X, Zhang S C, Sun Z, Kong W, et al. Effect of spraying parameters of unmanned aerial vehicle on droplets deposition distribution of maize canopies. Transactions of the CSAE, 2014; 30(5): 50-56. (in Chinese)

[3] Qin W C, Qiu B J, Xue X Y, Chen C, Xu Z F, Zhou Q Q. Droplet deposition and control effect of insecticides sprayed with an unmanned aerial vehicle against plant hoppers. Crop Protection, 2016; 85: 79-88.

[4] Xue X Y, Lan Y B, Sun Z, Chang C, Hoffmann W C. Develop an unmanned aerial vehicle based automatic aerial spraying system. Computers \& Electronics in Agriculture, 2016; 128: 58-66.

[5] Lan Y B, Chen S D. Current status and trends of plant protection UAV and its spraying technology in China. Int. J. Precis. Agric. Aviat., 2018; 1(1): 1-9.

[6] Xu Y, Xue X Y, Zhu S, Chang C, Gu W, Chen C, et al. Online spraying quality assessment system of plant protection unmanned aerial vehicle based on Android client. Computers \& Electronics in Agriculture, 2019; 166: 104938. doi: 10.1016/j.compag.2019.104938.

[7] Zhou Z Y, Ming R, Zang Y, He X G, Luo X W, Lan Y B. Development status and countermeasures of agricultural aviation in China. Transactions of the CSAE, 2017; 33(20): 1-13. (in Chinese)

[8] Gong C Y, Liu T J. Present situation analysis and industrial development of agricultural plant protection in unmanned aerial vehicle. Agricultural Development \& Equipments, 2016; 9: 136-150. (in Chinese)

[9] He X K, Bonds J. Herbst A, Langenakens J. Recent development of unmanned aerial vehicle for plant protection in East Asia. Int J Agric \& Biol Eng, 2017; 10(3): 18-30.

[10] Yang F B, Xue X Y, Cai C, Sun Z, Zhou Q Q. Numerical simulation and analysis on spray drift movement of multirotor plant protection unmanned aerial vehicle. Energies, 2018; 11(9): 1-20.

[11] Huang Y, Zhan W, Fritz, B K, Thomson S J. Optimizing selection of controllable variables to minimize downwind drift from aerially applied sprays. Applied Engineering in Agriculture, 2012; 28(3): 307-314.

[12] Qiu B J, Wang L W, Cai D L, Wu J H, Ding G R, Guan X P. Effects of flight altitude and speed of unmanned helicopter on spray deposition uniform. Transactions of the CSAE, 2013; 29(24): 25-32. (in Chinese)

[13] Xue X Y, Tu K, Qin W C, Lan Y B, Zhang H H. Drift and deposition of ultra-low altitude and low volume application in paddy field. Int J Agric \& Biol Eng, 2014; 7(4): 23-28.

[14] Al-Heidary M, Douzals J P, Sinfort C, Vallet A. Influence of spray characteristics on potential spray drift of field crop sprayers: a literature review. Crop Protection, 2014; 63:120-130.

[15] Zhang S C, Xue X Y, Qin W C, Sun Z, Ding S M, Zhou L X. Simulation and experimental verification of aerial spraying drift on N-3 unmanned spraying helicopter. Transactions of the CSAE, 2015; 31(3): 87-93. (in Chinese)

[16] Hou C J, Tang Y, Luo S M, Lin J T, He Y, Zhuang J J, et al. Optimization of control parameters of droplet density in citrus trees using UAVs and the Taguchi method. Int J Agric \& Biol Eng, 2019; 12(4): 1-9.

[17] Wang X N, He X K, Wang C L, Wang Z C, Li L L, Wang S L, et al Spray drift characteristics of fuel powered single-rotor UAV for plant protection. Transactions of the CSAE, 2017; 33(1): 117-123. (in Chinese)

[18] Song J L, Liu Y, Liu Y J, He X K, Li Y N, Wang C L, et al. Effective spray swath width determination of aerial spraying using unmanned aerial vehicle. Journal of China Agricultural University, 2017; 22(10): 126-132. (in Chinese)

[19] Chen S D, Lan Y B, Li J Y, Xu X J, Wang Z G, Peng B. Evaluation and test of effective spraying width of aerial spraying on plant protection UAV. Transactions of the CSAE, 2017; 33(7): 82-90. (in Chinese)

[20] Yang S L, Yang X B, Mo J Y. The application of unmanned aircraft systems to plant protection in China. Precision Agriculture, 2018; 19(2): 278-292.

[21] Zhang D Y, Chen L P, Zhang R R, Xu G, Lan Y B, Wesley C H, et al Evaluating effective swath width and droplet distribution of aerial spraying systems on M-18B and Thrush 510G airplanes. Int J Agric \& Biol Eng, 2015; 8(2): 21-30.

[22] Ministry of Agriculture and Rural Affairs of China. Technical specification of quality evaluation for crop protection UAS. NY/T3213-2018, 2018.

[23] Zhu H P, Salyani M, Fox R D. A portable scanning system for evaluation of spray deposit distribution. Computers \& Electronics in Agriculture, 
2011; 76(1): 38-43.

[24] Smith D B. Uniformity and recovery of broadcast spray using fan nozzles. Transactions of the ASAE, 1992; 35(1):39-44.

[25] Cao S Q, Luo H S, Jin M A, Jin S L, Duan X Y, Zhou Y L, et al. Intercropping influenced the occurrence of stripe rust and powdery mildew in wheat. Crop Protection, 2015; 70: 40-46.

[26] Dweba C C, Figlan S, Shimelis H A, Motaung T E, Sydenham S, Mwadzingeni L, et al. Fusarium head blight of wheat: Pathogenesis and control strategies. Crop Protection. 2017; 91: 114-122.

[27] Afridi K, Khan N U, Gul S, Bibi Z, Ali S, Ali N, et al. Genetic characterization of stripe rust and yield traits in bread wheat. Int. J. Agric. Biol., 2019; 21(3): 621-629.

[28] Ye X L, Li J, Cheng Y K, Yao F J, Long L, Yu C, et al. Genome-wide association study of resistance to stripe rust (Puccinia striiformis f. sp. tritici) in Sichuan wheat. BMC Plant Biology, 2019; 19(1): 147.

[29] Ma Z H. Researches and control of wheat stripe rust in China. Journal of Plant Protection, 2018; 45(1): 1-6. (in Chinese)

[30] Lei Y, Yao Z F, He D J. Design and experiment of micro-image remote acquisition system of uredinispores of puccinia striiformis f. sp. tritici. Transactions of the CSAM, 2018; 49 (11): 39-47. (in Chinese)

[31] Kertho A, Mamidi S, Bonman J M, Mcclean P E, Acevedo M Genome-wide association mapping for resistance to leaf and stripe rust in winter-habit hexaploid wheat landraces. Plos One, 2015; 10, e0129580.

[32] Li T X. Research progress of wheat powdery mildew forecasting method. Meteorological and Environmental Sciences, 2013; 36(3): 44-48. (in Chinese)

[33] Liu N, Lei Y, Zhang M, Zheng W, Shi Y, Qi X, et al. Latent infection of powdery mildew on volunteer wheat in Sichuan Province, China. Plant Disease, 2019; 103(6): 1084-1091.

[34] Zou Y F, Qiao H B, Cao X R, Liu W, Fan J R, Song Y L, et al Regionalization of wheat powdery mildew oversummering in China based on digital elevation. Journal of Integrative Agriculture, 2018; 17(4): 901-910.

[35] Huang C, Jiang Y Y, Wu J W, Qiu K, Yang J J. Occurrence and characteristics and reason analysis of wheat head blight in 2018 in China. Plant Protection, 2019; 45(2): 160-163. (in Chinese) 